\title{
INSTAGRAM: O PERFIL DA REDE DE CONTATOS QUE ATIVA O CONSUMO DE USUÁRIOS
}

Maria Naftally Dantas Barbosa ${ }^{1}$

Yákara Vasconcelos Pereira ${ }^{2}$

Karla Rosane Do Amaral Demoly ${ }^{1}$

\footnotetext{
${ }^{1}$ Universidade Federal Rural do Semi-Árido

${ }^{2}$ Universidade Federal de Pernambuco - UFPE
} 


\section{INSTAGRAM: O PERFIL DA REDE DE CONTATOS QUE ATIVA O CONSUMO DE USUÁRIOS}

Resumo: Esta investigação possui o objetivo de verificar o perfil da rede de contatos que ativa o consumo no Instagram, tendo em vista que representações sociais também são utilizadas como um aspecto ativador. Um estudo de caso qualitativo foi realizado com os usuários ativos em duas etapas: entrevista coletiva e individuais. Ao todo, 33 sujeitos participaram das entrevistas semiestruturadas, que foram examinadas por meio da análise de conteúdo com apoio Atlas.ti. Foi possível identificar que as publicações da família, amigos e artistas/influenciadores digitais são as que os usuários mais consideram no momento de decisão de compra, entretanto, esses estímulos agem apenas como um auxílio, ajudando-os a filtrar as informações, avaliar as alternativas e conduzindo-os à escolha final. Com isso, essa pesquisa contribuirá para a tomada decisão de empreendedores que atuam digitalmente, visto que ao se identificar o perfil dos usuários e seu comportamento de consumo, essas informações orientarão futuras estratégias empresariais.

Palavras-chave: Ativação do Consumo. Comportamento do Consumidor. Rede de Contatos. Instagram.

\section{$1 \quad$ Introdução}

$\mathrm{O}$ ambiente virtual possui papel de destaque na capacidade de transmitir e disseminar informações. Anteriormente se as relações sociais aconteciam em um contexto que demandava a presença física das pessoas, com a internet as possibilidades de conversação, criação e colaboração vêm se ampliando, a exemplo da mediação entre os indivíduos possibilitada por computadores (PRIMO, 2007; SOLOMON, 2016). Essa comunicação mediada pelo computador ganhou espaço graças à tecnologia da informação que modificou a forma com que as pessoas se comunicam, apresentando novos modelos de interação e agrupamentos sociais (RECUERO, 2009).

Nessa perspectiva, pode-se dizer que a conversação mediada que estabelecem as trocas informacionais originam às redes sociais digitais (RECUERO, 2009). Segundo Hermida et al., (2011), os usuários se expressam de forma objetiva, como uma espécie de alto-falante, referindo-se à quantidade de pessoas que alcançam em pouco tempo e à atenção que conseguem proporcionar ao conteúdo da mensagem.

Autores como Ioanãs e Stoica (2014) afirmam que os usuários de canais de redes sociais têm a necessidade de estabelecer e manter contato com outros usuários como forma de dar e receber apoio social, amizade e intimidade. Em decorrência disso, a conectividade interpessoal provocada pelas redes sociais permite que os amigos virtuais dos usuários estejam inseridos nos grupos de referência (DJAFAROVA; RUSHWORTH, 2016). Nesse caso, são chamados de grupos de referência virtuais, pois são formados em comunidades virtuais, onde as interações são estabelecidas por relações sociais intermediadas (SCHMIDT et al., 2018).

No campo de pesquisa do comportamento do consumidor, os grupos de referência são conceituados como grupos sociais que possuem papel importante na formação de atitudes e comportamentos de outras pessoas, afetando o processo de decisão de compra de produtos e 
marcas (DJAFAROVA; RUSHWORTH, 2016). Pode-se dizer que são grupos (formados por uma ou mais pessoas) que atuam como referência a um indivíduo no processo de compra, permitindo que esses indivíduos realizem uma comparação direta com seu estilo de vida, desejos e hábitos de consumo, e, por esse motivo, influenciam a imagem que o consumidor tem de si e de seu comportamento (MASHHADI; HASHEMIAMIN, 2017). É importante ressaltar que pertencem a esses grupos pessoas conhecidas, como família e amigos, mas também pessoas desconhecidas que o consumidor se inspira e confia (MASHHADI; HASHEMIAMIN, 2017).

Apesar de fazerem parte mais da vida dos jovens, as redes sociais podem influenciar o comportamento de consumo de pessoas com diferentes idades. Essa prática de recomendações de amigos, compartilhamento de opiniões e conselhos relacionados ao consumo pode gerar confiança e influenciar negativa ou positivamente a intenção de compra. Nesse caso, pela capacidade de exercerem controle sobre o conteúdo de suas próprias páginas de relacionamento com as quais interagem, os usuários deixam de ser apenas receptores passivos para se tornarem criadores ativos de informação de consumo (TUBENCHLAK et al., 2015; SOLOMON, 2016).

No caso do Instagram, os sujeitos são divididos entre seguidores (perfis que seguem o usuário) e seguidos (perfis que o usuário segue). Esse recurso constitui a rede de contatos do usuário, permitindo que ele seja seguido e siga perfis de conhecidos, personalidades e até mesmo de outras pessoas, as quais se interesse em acompanhar o conteúdo, podendo curtir as publicações favoritas e fazer comentários. Ainda nesse sentido, o Instagram pode incentivar os seus usuários a compartilharem conteúdo positivo, facilitando a comunicação entre consumidores e, com isso, aumentando o potencial de compartilhamento de experiências pessoais em diferentes dispositivos e formatos (fotos e vídeos), contribuindo para que haja a ativação do consumo (WATERLOO et al., 2018).

A ativação do consumidor sobre algum objeto depende da força da associação com as ideias relacionadas a ele (FAZIO et al,, 1986), incluindo os contatos importantes dentro de um mesmo ambiente social (DIJKSTERHUIS et al., 2005), tendo em vista que pessoas e representações sociais também são utilizadas como um aspecto ativador (PACHECO JÚNIOR et al., 2015). Nesse caso, a representação de pessoas importantes pode levar à ativação automática do consumo e influenciar o comportamento do consumidor, fazendo-o assumir atitudes, estilos e gostos parecidos, como uma espécie de imitação (FAZIO et al., 1986; DIJKSTERHUIS et. al., 2005).

Mesmo sendo um assunto do cotidiano da sociedade contemporânea, observa-se poucos estudos sobre o processo de ativação do consumo no contexto das redes sociais digitais, onde os usuários interagem diretamente com o conteúdo gerado por outro usuário (KAPETANAKI; BERTELE; BRENNAN, 2017). E com isso, identifica-se a necessidade de compreender: quais são os perfis seguidos pelos usuários e quais as influências que eles exercem sobre a ativação do consumo? Diante disso, esta investigação possui o objetivo central de verificar o perfil da rede de contatos que ativa o consumo.

Dessa forma, entende-se que esse trabalho contribuirá para a tomada decisão de empreendedores que atuam no ambiente digital, visto que ao se identificar o perfil dos usuários presentes no Instagram e seu comportamento de consumo, essas informações orientarão as estratégias que deverão ser implementadas pela empresa para atingir seu público-alvo (ZAMPIER, TAKAHASHI, 2011). 


\section{$2 \quad$ Referencial Teórico}

\subsection{Grupos de Referência}

$\mathrm{O}$ ambiente de redes sociais facilitou a habilidade dos consumidores de acompanhar marcas de interesse e se conectar com elas. Nelas, o consumidor interage com a empresa, tira dúvidas, faz reclamações, obtém informações sobre os produtos e faz recomendação para outros usuários, estimulando a criação de novos contatos ou a manutenção de contatos antigos com amigos ou conhecidos.

Por sua vez, estas redes sociais possibilitam o aparecimento de grupos virtuais diferentes dos grupos de referência tradicionais devido à diversidade de informações, expondo os usuários a opiniões, recomendações e relações de amizade de forma interativa (SCARABOTO; ROSSI; COSTA, 2012).

Um grupo de referência é formado por uma ou mais pessoas que possuem influência relevante e significativa nos hábitos, estilos de vida e criação de valor de outros sujeitos (PARK; LESSING, 1977; SCARABOTO; ROSSI; COSTA, 2012). Nota-se que em algumas situações, é utilizado por um indivíduo como forma de se auto identificar, classificar ou comparar-se com membros que fazem parte de seu grupo social ou de grupos distintos (TURČÍNKOVÁ; MOISIDIS, 2011), ao qual não pertence ainda, mas que aspira pertencer.

De acordo com Solomon (2016), os indivíduos são frequentemente influenciados pela opinião de outras pessoas na escolha e utilização de produtos e serviços, isso porque desejam ser aceitos por estas. Com isso, fazem parte dos grupos de referência a familiares, amigos, associações profissionais e religiosas, celebridades, formadores de opinião, entre outros (RADONSA et al., 2014; SOLOMON, 2016).

Diante do conteúdo exposto, foi possível identificar que os grupos de referência são classificados de acordo com algumas variáveis, quais sejam: aspiracionais, dissociativos, primários e secundários.

O primeiro item são os grupos aspiracionais, definidos como grupos que o indivíduo deseja fazer parte, inspirando-se em nas atitudes, estilo de vida e valores de seus membros (RADONSA et al., 2014). Nesse caso, os consumidores sentem uma necessidade de pertencimento e usam pessoas que eles admiram como fonte de informação para avaliar suas opiniões e crenças sobre o mundo (ZUCCO; PIANEZZER; FALASTER, 2017). Destacam-se, nesse grupo, as celebridades e os formadores de opinião, que são pessoas reconhecidas e de referência para um determinado público que o admira e deseja copiar (BHARGAVA, 2015; SCHMIDT et al., 2018).

O segundo grupo são os dissociativos, caracterizados como grupos dos quais os indivíduos não querem estar associados por motivos particulares, pois seus valores e comportamentos não são bem aceitos na sociedade (RADONSA et al., 2014; SCHMIDT et al., 2018).

Os grupos primários são os de afiliação, ou seja, aqueles que o indivíduo já pertence. Nesse grupo, há maior associação e interação entre os membros, com culturas semelhantes e atividades frequentemente compartilhadas (RADONSA et al., 2014). São exemplos desse grupo a família, os vizinhos, amigos próximos e colegas de trabalho (SCARABOTO; ROSSI; COSTA, 2012). 
Por fim, os grupos secundários são descritos como aqueles que os indivíduos possuem relações temporárias, com menos contato e, consequentemente, menos influência sobre seu comportamento (RADONSA et al., 2014). Estão incluídos a esses grupos os amigos distantes, grupos religiosos e associações (SCARABOTO; ROSSI; COSTA, 2012).

Em relação à influência social dos grupos de referência, Radonsa et al., (2014) enfatizam que possui efeito significativo no comportamento do consumidor e definem como a forma com que os indivíduos compreendem a influência que as pessoas, dentro de seu círculo social, exercem sobre ele. Isso permite que os indivíduos se comportem conforme seus grupos de referência e modifiquem suas decisões com base na avaliação de outros (BEARDEN, NETEMEYER, TEEL, 1989).

No estudo clássico, Park e Lessing (1977) desenvolveram um modelo que contempla três tipos distintos de influência social motivacional dos grupos de referência: a informativa, utilitária e a influência expressiva de valor. O primeiro tipo de influência é a informativa, que estimula a busca de informações e avaliação dos atributos de produtos e serviços, principalmente com especialistas ou com pessoas que já o tenham experimentado (BEARDEN; NETEMEYER; TEEL, 1989; RADONSA et al., 2014). Essa influência é aceita pelo indivíduo e tem o objetivo de aumentar o seu conhecimento sobre o produto e prepará-lo para o momento da compra. É importante salientar que nesse processo de influência não é necessário que o indivíduo tenha interação real com o grupo de referência, mas apenas conheça e confie em suas informações (PARK; LESSING, 1977).

Por sua vez, a influência utilitária está relacionada à conformidade que um indivíduo deve ter com as expectativas das outras pessoas, buscando o comportamento reconhecido, ser recompensado ou evitar uma punição (PARK; LESSING, 1977; RADONSA et al., 2014).

Por fim, a influência expressiva de valor acontece quando o indivíduo entende e aceita a influência de outra pessoa a qual se identifica. Nesse caso, ele se apoia em grupos de referência que gostaria de pertencer, adotando seu estilo de vida e recomendações de consumo, com o intuito de se expressar, enaltecer o seu ego, expor o que gostaria de ter/ser e, consequentemente, melhorar sua imagem (PARK; LESSING, 1977; RADONSA et al., 2014). Essa influência está ligada ao status adquirido e, nesse caso, os consumidores são mais propensos a buscar a aprovação social por meio da aquisição e uso dos produtos e marcas que outras pessoas utilizam (CHU; KIM, 2011).

É importante destacar que os três tipos de influência pressionam o indivíduo a modificar seu comportamento, o que implica dizer que quanto maior o envolvimento com um determinado grupo de referência, maior será a possibilidade de adquirir as opiniões, crenças e atitudes positivas ou negativas desse grupo em específico, o que constitui o priming social.

\subsection{Priming Social}

O priming social, que é constituído por representações sociais de pessoas, também pode ser considerado um estímulo ativador. Nesse caso, pessoas associadas a outras podem levar a ativação automática de uma ação, como por exemplo, ao observar o comportamento de parentes, amigos e pessoas importantes, o indivíduo pode automaticamente começar a agir como essas pessoas e ter os mesmos hábitos de consumo (DIJKSTERHUIS, et al., 2005; PACHECO JÚNIOR et al., 2015). Com isso, observa-se que as publicações de contatos virtuais lançadas em redes sociais contribuem para ativar o interesse de consumo dos usuários, isso 
porque no momento em que são visualizadas criam relações afetivas e cognitivas convincentes que estimulam o comportamento (CHU; KIM, 2011).

Por meio da revisão de literatura, é possível apresentar os principais fatores sociais que podem influenciar o comportamento do consumidor e fortalecer a ativação do consumo nas publicações dos perfis que os usuários seguem, quais sejam: confiança, homofilia, laços fortes, influência interpessoal - informativa e normativa (CHU; KIM, 2011; ZUCCO; PIANEZZER; FALASTER, 2017).

Um dos aspectos que pode motivar o comportamento de compra dos usuários nas redes sociais é a confiança na fonte da mensagem. O estudo de Kreft e Karwat (2017) confirma que mesmo com o amplo acesso a várias informações e recomendações publicadas em redes sociais e a tendência da livre troca de experiências, os consumidores ainda buscam primeiramente as opiniões de seus amigos no momento da avaliação da compra, isso devido ao elevado nível de engajamento entre eles e credibilidade da mensagem (BHAYANI, 2016). Com isso, pode-se dizer que o fator confiança é a categoria que mais influencia o comportamento, pois os consumidores confiam nas indicações de seus amigos e os têm como referência na tomada de decisão de compra (ZUCCO, PIANEZZER; FALASTER, 2017; ASTUTI; PUTRI, 2018).

A relação afetiva e cognitiva criada pela publicação é ainda mais forte quando os usuários compartilham características semelhantes (sócio demográficas, raça, idade, crenças e atitudes), definidas como homofilia ou relações homofílicas (BROWN; BRODERICK; LEE, 2007; CHU; KIM, 2011; BHAYANI, 2016; HOFFMANN, 2017). As relações de homofilia passam credibilidade e força, pois os contatos de uma mesma rede social agrupados por interesses similares tendem a ser mais facilmente influenciados uns pelos outros, podendo despertar intenções e atitudes de consumo (BROWN; BRODERICK; LEE, 2007; HOFFMANN, 2017).

Também foi possível identificar que a confiança e a homofilia geram laços fortes na rede. Os laços sociais são formados pelas interações entre os indivíduos e sua rede de relacionamentos e são constituídos por relações mais próximas (ZUCCO, PIANEZZER; FALASTER, 2017), como amigos próximos, amigos regulares e familiares (WATERLOO et al., 2018). Esses laços são compostos pela força do tempo, emocional, intimidade e relacionamento entre os usuários, podendo afetar diretamente a comunicação online (GRANOVETTER, 1973; ZUCCO; PIANEZZER; FALASTER, 2017). Com isso, pode-se interpretar que os sujeitos mais próximos são considerados referência e, por isso, exercem maior influência na intenção de compra dos usuários. Nesse quesito, os consumidores tendem a dar maior credibilidade e serem influenciados por aqueles que também mantêm contato presencial.

A expressividade também pode ter um papel de destaque na ativação do consumo, visto que os usuários expressivos são os mais ativos nas redes sociais e são aqueles que gostam de se expressar e de fornecer informações sobre sua vida. Os sujeitos desses perfis mantêm uma relação próxima a sua rede de contatos e ao compartilhar suas experiências com produtos e serviços podem ativar e despertar o desejo de consumo das pessoas (CHU; KIM, 2011; VINEREAN et al., 2013; TUBENCHLAK et al., 2015).

\section{$3 \quad$ Procedimentos Metodológicos}

Para esta investigação, optou-se pela pesquisa de abordagem qualitativa, que busca a compreensão de um fenômeno, baseando-se na coleta de informações, interpretação e descrição de sujeitos e o seu contexto (STAKE, 2011; GODOY, 1995a). A abordagem está adequada para o estudo, apresentado como justificativa de escolha o fato da investigação ser centrada no 
comportamento humano, extraindo dados a respeito dos sentimentos, motivações e percepções de cada sujeito estudado e não apenas apresentando um aspecto geral (COOPER; SCHINDLER, 2011).

Para obter as informações a fim de responder à pergunta da pesquisa, optou-se por realizar um estudo de caso, conceituado por Yin (2015) como uma pesquisa empírica, realizada de forma minuciosa e aprofundada sobre um tema contemporâneo, desenvolvido diante do desejo de se compreender a sociedade. É realizado quando o pesquisador apresenta pouco controle acerca dos eventos ocorridos, entretanto, permite revelar amplo e detalhado conhecimento sobre algum fato real do presente (GODOY, 1995b). Assim, esta é uma pesquisa de abordagem qualitativa, desenvolvida a partir de um estudo de caso com usuários do Instagram.

Por se tratar de um estudo de caso qualitativo, foram utilizadas entrevistas semiestruturadas (COPPER; SCHINDLER, 2011) como técnica de coleta de dados, por ser considerada "[...] uma estratégia fundamental da investigação qualitativa" (GODOY, 1995a, p. 61). Em vista disso, essa pesquisa utilizou dois tipos de entrevistas, sendo realizadas em duas etapas distintas: entrevista em grupo e entrevista individual. Anteriormente ao período de coleta de dados, os dois roteiros de entrevistas foram validados e aprimorados na fase do estudo piloto.

Dessa forma, a entrevista em grupo foi realizada na primeira etapa da coleta de dados, no dia 27 de setembro de 2018, com um grupo de 6 pessoas e seguiu um roteiro para obter ampla variedade de informações em um curto período de tempo (COOPER; SCHINDLER, 2011). A entrevista durou cerca de 1 hora e 24 minutos e foi conduzida por uma das pesquisadoras com o intuito de realizar a mediação e registrar as informações, além disso foram usados dois gravadores que colaboraram na transcrição da entrevista posteriormente.

Para participar da entrevista em grupo foram determinados os seguintes critérios: a) ser maior de 18 anos e b) ser usuário da rede social Instagram. Com isso, a entrevista foi composta por 6 sujeitos heterogêneos, isto é, com variedade de opiniões, histórico de vida e comportamentos diferentes (COOPER; SCHINDLER, 2011), totalizando 3 mulheres e 3 homens, com idades entre 21 e 39 anos, sendo 5 respondentes do Rio Grande do Norte e 1 do Ceará. Todos são estudantes do curso de Publicidade e Propaganda da UERN e trabalham na área, permitindo o acesso à temática abordada.

Como forma de ampliar as respostas e obter informações mais específicas e detalhadas sobre as experiências dos usuários na rede social Instagram, realizou-se a etapa 2, constituída por entrevista semiestruturada individual com 27 pessoas originadas de cada estado brasileiro, em momentos isolados e horários pré-agendados, e também seguiu um roteiro de entrevista semiestruturada. Como forma de alcançar todos os sujeitos da pesquisa, as entrevistas ocorreram presencialmente, via Skype, Whatsapp e por telefone, foram gravadas e transcritas, totalizando 684 minutos.

Portanto, nessa fase foram entrevistados 27 sujeitos correspondentes a cada estado do Brasil, sendo 21 mulheres e 6 homens, com idade entre 18 e 50 anos. Os respondentes ainda possuem diferentes níveis de escolaridade e profissão/ocupação, o que contribui na abrangência e diferenciação das respostas coletadas.

É importante esclarecer que o critério de seleção dos sujeitos foi do tipo bola de neve, que utiliza cadeias de referência dos participantes já existentes (FLICK, 2009). Dessa forma, os respondentes da pesquisa indicaram novos contatos de sua rede pessoal com as características desejadas da pesquisa para participar das entrevistas. Já sobre a quantidade exata de 
participantes das sessões de entrevistas individuais foi definida quando se obteve a saturação das informações, que ocorre quando não há mais novidade nas respostas coletadas (PAIVA JUNIOR; LEÃO; MELO, 2011).

Após a fase de coleta de dados foi iniciada a análise, considerada por Gomes (2001) como a etapa de tratamento dos dados e interpretação dos resultados obtidos. Esta pesquisa adotou a técnica de análise de conteúdo para realizar a interpretação dos dados, auxiliando na descrição, inferência e interpretação (BARDIN, 2011) dos dados coletados nas entrevistas, buscando obter conexões com o referencial teórico abordado na pesquisa.

Ainda de acordo com Bardin (2011), a análise dos dados foi composta por três etapas fundamentais: pré-análise, exploração do material e tratamento dos resultados. A pré-análise é considerada a fase de organização. Nessa etapa, foi definido o escopo da pesquisa e realizada uma releitura do material, para retirar os erros de digitação e vícios de linguagem dos respondentes.

A exploração do material é a fase de administração das decisões tomadas na pré-análise. Consiste na leitura aprofundada do material, buscando codificar, classificar e categorizar (BARDIN, 2011). É oportuno ressaltar que nessa fase, no momento da codificação, foram levantados alguns construtos para enriquecer a análise. Para isso, foi definido o recorte, que corresponde a escolha das unidades de registro, os quais foram selecionadas palavras-chave e os temas mais recorrentes (BARDIN, 2011).

A última etapa corresponde ao tratamento dos resultados obtidos e interpretação. Para Bardin (2011), essa é a fase de tratar os dados de modo que sejam significativos e válidos. Utiliza técnicas qualitativas e/ou quantitativas para ajudar na interpretação, buscando confirmar os pressupostos da pesquisa e alcançar os objetivos inicialmente propostos. Para isso, foram utilizadas, nesta pesquisa, redes para auxiliar na interpretação dos resultados.

Ressalta-se que na etapa de análise dos dados foi utilizado o ATLAS.ti na versão 8, ferramenta que contribui para a realização de pesquisas que aplicam a análise de conteúdo (WALTER; BACH, 2015). Dentre as funcionalidades do ATLAS.ti está o tratamento de grande quantidade de informações, o que facilita a sua operacionalização e, consequentemente, o trabalho do pesquisador (LEITE; MORAES; SALAZAR, 2016), pois torna o processo mais ágil. Com o programa, foi possível acessar as transcrições, analisar, codificar e categorizar as respostas dos entrevistados.

\section{$4 \quad$ Análise dos Resultados}

Como foi visto anteriormente, a rede de contatos tem papel importante no comportamento de consumo, pois representam as relações de confiança e referência dos usuários do Instagram (BOYD, 2006; TUBENCHLAK et al., 2015). Dessa forma, esta seção busca verificar o perfil da rede de contatos que ativam o consumo. De acordo com a análise, foi possível identificar os contatos que os usuários seguem e consideram na hora de consumir, esses, representados por família, amigos, artistas e influenciadores digitais. Ainda se percebeu, com base nos perfis citados pelos entrevistados, que esses são definidos pelo grau de expressividade, laços fortes, confiança, homofilia e experiência. A figura 1 expressa os resultados que atendem ao segundo objetivo específico, dividida em duas categorias, a saber: seguidos e perfil.

Figura 1 - Identificação da rede de contatos. 


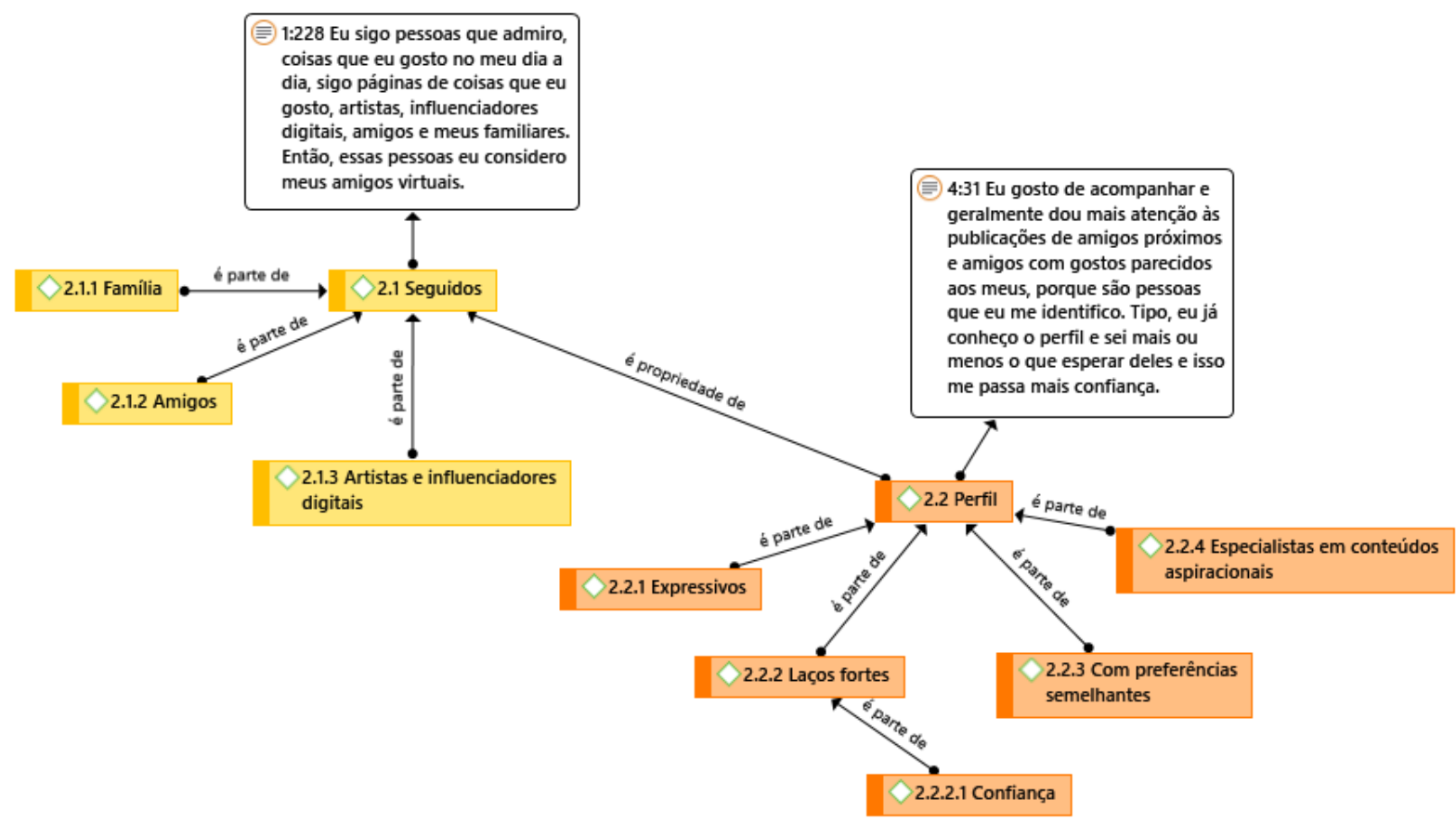

Fonte: Elaborado pelas autoras com ATLAS.ti (2019).

A primeira categoria citada aborda os principais contatos dos entrevistados, determinados como aqueles que seguem no Instagram e dão maior atenção às publicações. O primeiro grupo corresponde à família dos usuários, pessoas as quais eles têm maior proximidade e que fazem parte de suas vidas (Entrevistada 1). São familiares que costumam mostrar a sua vida nas redes sociais e são constantemente acompanhados pelos usuários, como relata a Entrevistada 1: "Eu sigo pessoas que fazem parte da minha vida, como meus familiares. Eu não sigo alguém, por exemplo, só porque eu acho bonita, eu preciso ter uma relação. Então, por isso eu curto mais as publicações da minha família, porque eu já conheço e gosto do conteúdo que eles postam". Esse pensamento reforça a perspectiva de que o Instagram facilita a manutenção dos relacionamentos com os integrantes do grupo de afiliação/primário, no caso a família, e, além disso, reforçam que o impacto desse grupo sobre o comportamento dos sujeitos é significativo devido às relações estreitas (TURČ́́NKOVÁ; MOISIDIS, 2011; RADONSA et al., 2014).

Os amigos próximos também fazem parte da referência primária devido a maior associação entre seus membros (SCARABOTO; ROSSI; COSTA, 2012; RADONSA et al., 2014). Esse grupo foi citado mais vezes pelos entrevistados, o que implica dizer que são os perfis que os usuários mais seguem, interagem, buscam informações e trocam experiências, como detalha o entrevistado a seguir:

Eu sigo mais amigos próximos, pessoas que eu gosto de compartilhar minha vida, meus momentos. São essas pessoas próximas a mim que eu gosto de saber o que estão fazendo, o que estão consumindo, aonde estão indo, que eu busco informações sobre produtos. São pessoas que eu tenho um afeto e eu sei que tem afeto por mim, porque eu quero postar coisas que sejam relevantes para mim e que sejam para quem eu estou compartilhando. Então, com certeza, eu reparo mais nas publicações dos meus amigos e fico mais atento ao conteúdo que eles postam. (Entrevistado 16_SE). 
A opinião acima reflete que a relação construída no Instagram entre amigos próximos pode contribuir para uma grande influência na decisão de compra, por serem, em certos casos, as principais fontes de informação dos usuários, achados que estão em consonância com Komaladewi e Indika (2017) e Schmidt et al., (2018).

O último grupo mencionado se constitui pelos artistas e influenciadores digitais. Tratamse de celebridades e formadores de opinião online, que possuem muitos seguidores nas redes sociais e fazem parte dos grupos aspiracionais (BHARGAVA, 2015; SCHMIDT et al., 2018). Para a Entrevistada 33 RN: "[...] se você vê que uma blogueira está indicando uma marca de perfume, um produto de cabelo, eu vou entender que aquilo é bom, porque é alguém que tem influência, usa e está indicando para as pessoas, então, com certeza isso, tem muito peso [...]". Essa evidência confirma a compreensão de alguns autores que afirmam que os produtos divulgados por personalidades são bem mais aceitos e avaliados positivamente, devido ao fato deles pertencerem a um grupo social que os usuários também aspiram fazer parte (DJAFAROVA; RUSHWORTH, 2016; NUNES et al., 2017).

Depois de identificados os contatos seguidos responsáveis por ativar o consumo dos usuários, investigou-se o seu perfil. A explicação é iniciada pelos expressivos, característica que os respondentes utilizaram para descrevê-los, tendo em vista que estão sempre ativos nas redes sociais, publicando constantemente sobre suas vidas, expondo o que vestem, o que comem e os lugares que frequentam, como menciona a Entrevistada 25_MG:

O povo que eu sigo daqui posta demais, são muito expressivos e já virou moda tirar foto pra postar. As pessoas gostam de ir para as festas e postar pra mostrar o que estão fazendo, os shows, as apresentações, fotos com amigos, mostrando com quem estão. Eles também postam como forma de propaganda também, fazem muitos recebidos, mostram o que ganharam e usam aquele produto, até as pessoas comuns que não são influenciadoras.

Essa expressividade dos contatos no Instagram mencionada pela entrevistada é responsável por contribuir para aumentar a relação de proximidade com os usuários, por estarem fornecendo informações sobre suas vidas a todo instante. Devido a essa forma de exposição são capazes de despertar o desejo de consumo nos usuários que visualizam suas publicações (CHU; KIM, 2011; VINEREAN et al., 2013; TUBENCHLAK et al., 2015).

Nesse quesito, nota-se certa controvérsia nas respostas dos entrevistados a respeito da influência dos perfis expressivos, principalmente daqueles que nasceram em um estado, mas vivem em outro, como é o caso da Entrevistada 12_PI: "[...] com certeza eu me sinto mais influenciada a consumir ao ver as publicações dos meus amigos daqui do Rio Grande do Norte, já que os meus amigos de lá publicam menos, os daqui são mais ativos e me influenciam mais". Já outros entrevistados têm opiniões contrárias e dizem serem mais influenciados por amigos do seu estado de origem, mesmo morando em outro, é o caso da Entrevistada 8_PB: “[...] os meus amigos de Campina Grande me influenciam mais, porque lá as publicações são mais chamativas, dos lugares que vão, as viagens que fazem, o que consomem. Lá tem mais variedade de lugares, então é mais interessante de acompanhar e chama mais a minha atenção". A respeito disso, nota-se que em alguns casos há uma maior afinidade dos usuários com os 
perfis seguidos de seu estado de origem, enquanto em outros, existe uma aproximação com os perfis das pessoas que residem em seu estado atual.

Outro perfil é formado por aqueles com quem os usuários possuem laços fortes. Os entrevistados afirmam dar mais atenção aos contatos que têm maior proximidade, mantendo uma relação que ultrapassa o virtual, ou seja, com quem têm também relação física/real diária (Entrevistado 13_PA, Entrevistada 17_RS e Entrevistada 31_AM). Com esses amigos, há mais liberdade de interação por meio de likes, comentários, directs e trocas de experiências (Entrevistado 16_SE e Entrevistada 22_AC). Portanto, esse resultado está no mesmo sentido da literatura quando expõe que os laços fortes no Instagram transmitem credibilidade e confiança, exercendo maior influência na intenção de compra dos usuários (GRANOVETTER, 1973; ZUCCO; PIANEZZER; FALASTER, 2017; WATERLOO et al., 2018).

A respeito da confiança, percebe-se que ela está diretamente relacionada ao grupo dos laços fortes, já que os entrevistados relataram sentir maior confiança nas opiniões e recomendações de daqueles que conhecem pessoalmente e têm maior afinidade, como explica o Entrevistado 24_TO: “[...] se uma pessoa próxima a mim me indicar um produto no Instagram e disser 'pode comprar que é bom', eu não teria dúvidas em comprar. É $100 \%$ certeza eu usar um produto se um amigo meu chegar e recomendar, porque são pessoas que eu confio". Com isso, esse relato permite entender que ao fazer uma compra, os usuários procuram primeiramente seus amigos mais próximos para buscar informações sobre produtos/serviços, pois, na maioria dos casos, são essas pessoas as quais possuem uma confiança mais significativa (BHAYANI, 2016; ZUCCO; PIANEZZER; FALASTER, 2017; KREFT; KARWAT, 2017; ASTUTI; PUTRI, 2018).

A quarta característica citada diz respeito àqueles com preferências semelhantes, definidos pelos autores como homofilia (BROWN; BRODERICK; LEE, 2007; CHU; KIM, 2011; BHAYANI, 2016; HOFFMANN, 2017). Assim sendo, os entrevistados mencionaram que seguem e dão mais atenção às publicações de contatos que se identificam, em termos de características físicas e opiniões, além de compartilharem os mesmos gostos para produtos e serviços.

Eu sigo muitos amigos, mas tenho que ver se a gente tem coisa em comum, por exemplo, eu acho que eu sou muita fascista, porque tem pessoas que eu quero tirar da minha vida por causa de política. Eu não sigo pessoas que eu tenho divergências. Então, eu acho que é por interesses próximos, coisas que eu compartilho, aí eu vou seguindo aquele perfil.

Por meio do relato anterior, é possível perceber que no Instagram, os usuários buscam estarem conectados a pessoas que compartilham do mesmo perfil, evitando seguir pessoas com opiniões contrárias. Além disso, essa característica expressa consonância com a abordagem teórica revisada no sentido que usuários agrupados pelos mesmos interesses têm maior probabilidade de serem influenciados uns pelo outros, tendo sua intenção de consumo despertada com mais facilidade (BROWN; BRODERICK; LEE, 2007; HOFFMANN, 2017), como explica o Entrevistado 9_SP: “[...] tenho alguns amigos com gostos parecidos com o meu para roupas, então eu vejo as publicações deles, acho legal o estilo e acabo indo no perfil da loja para saber mais informações". 
Por fim, estão os experientes em conteúdos aspiracionais, isto é, conteúdos que os usuários têm maior interesse e desejam saber mais. Essas pessoas são consideradas especialistas por terem conhecimento sobre determinado assunto, exercendo influência informativa sobre os demais usuários. "Quando quero comprar algo geralmente procuro especialistas. Se um amigo que entende sobre tecnologia, me recomendar um Iphone e me falar as vantagens do aparelho, ele vai me convencer, por ser uma pessoa especialista nesse assunto e saber mais do que eu" (Entrevistado 16_SE). Isso confirma que esse perfil de especialistas prepara o usuário para realizar uma comprar por fornecer mais informações sobre conteúdos de seu interesse (BEARDEN; NETEMEYER; TEEL, 1989; RADONSA et al., 2014).

Ainda nesse sentido, foi possível identificar os principais conteúdos aspiracionais dos usuários, quais sejam: (1) moda e beleza, (2) gastronomia, (3) viagens, (4) fitness, (5) arte, (6) música e (7) fotografia. Segundo a Entrevistada 29_RO, ela segue pessoas que postam sobre temas dos quais ela realmente gosta e tem maior interesse, ainda revela que isso acontece devido ao desejo de se inspirar no que está sendo publicado, como explica no relato a seguir: "[...] isso acontece por influência mesmo, por me espelhar na vida da pessoa, buscar referência de roupa, observar o estilo de se vestir e de se maquiar de determinadas pessoas, é uma forma de se inspirar."

A influência dos perfis seguidos sobre a tomada de decisão de compra dos usuários foi tema também retratado nessa análise. A figura 2 ilustra os tipos de influências mais encontrados, com base nos relatos dos entrevistados.

Figura 2 - Tipos de influência dos perfis seguidos. 


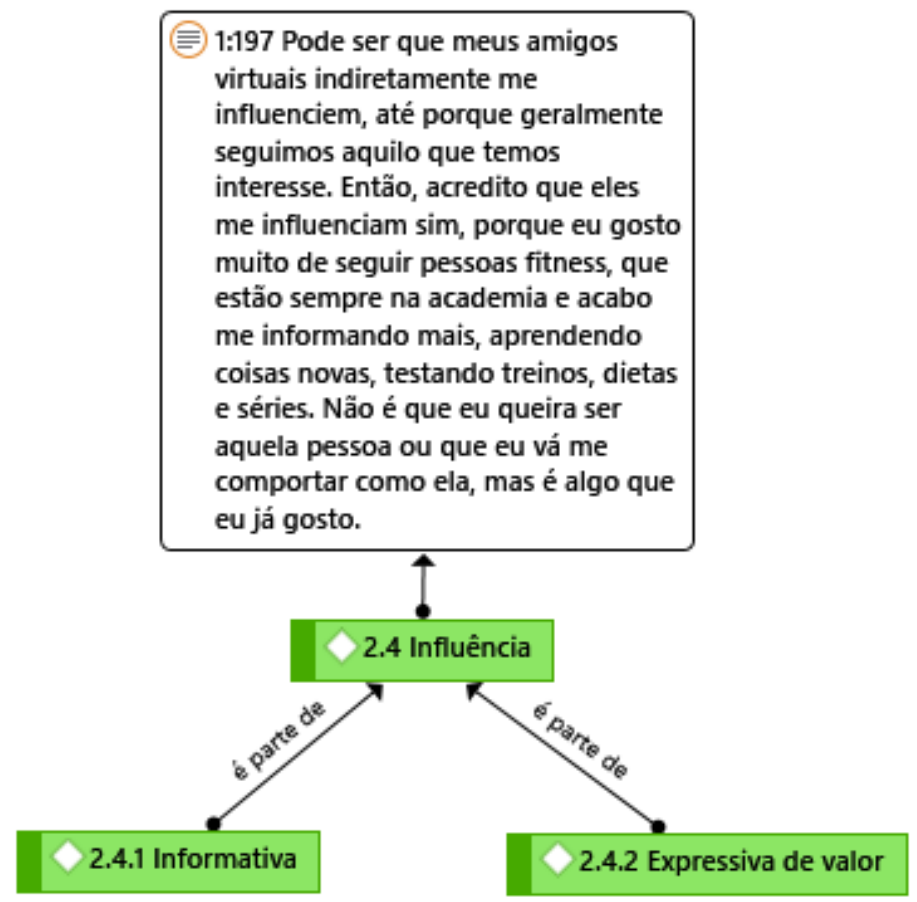

Fonte: Elaborado pelas autoras com ATLAS.ti (2019).

Dentre os tipos de influência dos perfis seguidos, por meio da análise foi possível perceber a presença da influência informativa e expressiva de valor. Sobre a primeira, os entrevistados responderam que os relatos de seus contatos seguidos ajudam em sua decisão, principalmente quando eles estão com dúvidas a respeito do produto. Isso acontece quando identificam que essas pessoas já experimentaram um produto específico e as procuram para obter mais informações, como explica a Entrevistada 32_PE: “[...] às vezes eu falo pra pessoa 'ah, eu vi que tu tens isso, o que você achou?', aí a pessoa me fala um pouco mais sobre o produto. Nunca eu compro só pela foto, eu sempre vou lá perguntar a pessoa como foi a experiência dela". Portanto, nota-se que a literatura é fortalecida, pois segundo alguns autores, os usuários buscam as publicações de seus contatos reais e virtuais para se informar sobre produtos e serviços e procuram ter suas decisões de compra orientadas por essas pessoas, inclusive para realizar comparações entre as opções existentes (RADONSA et al., 2014; SOLOMON, 2016; ZUCCO; PIANEZZER; FALASTER, 2017).

Por outro lado, o segundo tipo de influência encontrada foi a expressiva de valor. Sobre essa questão, os entrevistados relataram que em certos momentos se sentem atraídos a consumir o que está sendo publicado devido ao desejo de se parecer com as pessoas que fazem parte daquele mesmo grupo social, como explica a Entrevistada 27_AP: “[...] já comprei coisas por influência das publicações de pessoas específicas. Eu gostava muito do estilo dela, aí acabei me inspirando e comprando. Eu comprei porque eu queria ter a mesma coisa que a pessoa, era mais um passo pra ser como ela [...]” e confirma a Entrevistada 26_RR: “[...] hoje mesmo eu vi as fotos de um amigo nosso da família viajando e comentei com meu pai que minha meta de vida é ser igual a ele, viver viajando". Dessa forma, compreende-se que os resultados corroboram Park e Lessing (1977), Chu e Kim (2011) e Radonsa et al., (2014), pois há conformidade entre 
as expectativas dos usuários com o estilo de vida de seus contatos seguidos, afetando atitudes, normas e valores.

Portanto, por meio dos resultados foi possível identificar que as publicações da família, amigos e artistas/influenciadores digitais são as que os usuários mais consideram no momento de decisão de compra. Essas pessoas possuem o perfil de expressividade, proximidade, confiança, preferências semelhantes e especialidade. Esse resultado reforça a ideia de que o Instagram facilita a manutenção dos relacionamentos com os integrantes dos grupos de afiliação/primário (família e amigos próximos) e grupos aspiracionais (influenciadores digitais) (RADONSA et al., 2014; BHARGAVA, 2015; SCHMIDT et al., 2018).

\section{Considerações Finais}

Esta pesquisa partiu da seguinte problemática de pesquisa: quais os perfis seguidos pelos usuários e as influências que eles exercem sobre a ativação do consumo? Por meio da literatura, foram identificadas questões relevantes acerca do comportamento do consumidor nas redes sociais digitais e da teoria priming que ajudaram a compreender os processos de ativação do consumo, a relação dos usuários com sua rede de contatos e os seus efeitos na decisão de compra.

Em relação aos perfis seguidos, há a atuação dos expressivos na ativação do consumo, isso porque a expressividade estimula ainda mais a presença dos usuários na rede social e faz com que sejam mais expostos aos conteúdos produzidos por outros usuários, o que permite potencializar o desejo de compra. Em suma, quanto mais fotos são publicadas pelas pessoas seguidas, mais engajados ficam os usuários em acompanhar suas vidas e aspirar um estilo de vida parecido ou um produto que está inserido no contex to da publicação.

A respeito da tomada de decisão de compra, foi possível perceber que os usuários se sentem influenciados pelas publicações dos perfis que seguem, entretanto, esses estímulos agem apenas como um auxílio, ajudando-os a filtrar as informações, avaliar as alternativas e conduzindo-os à escolha final e não como um fator isolado. Dessa forma, compreende-se que a ativação não é um processo que ocorre isoladamente, mas é resultado do conjunto de informações que já estão armazenadas na memória do usuário e são acessadas no momento da exposição da publicação.

De uma perspectiva teórica, esta investigação permite algumas contribuições para a academia por trazer a discussão sobre o processo de ativação do consumo no contexto das redes sociais digitais. Isso implica dizer que os resultados desse estudo proporcionaram um conhecimento que vai além da literatura existente, revelando como ocorre a ativação do consumo, por meio de quais perspectivas, a influência que os perfis seguidos exercem sobre os usuários e os seus efeitos no comportamento dos sujeitos que utilizam essas plataformas.

Por outro lado, os resultados obtidos também contribuem para que empresas e profissionais que trabalham no setor digital estejam não apenas atentos em satisfazer as necessidades dos consumidores, como também reconheçam o conteúdo que é produzido por esses indivíduos em suas redes sociais, pelo fato de serem responsáveis por reforçar o consumo e auxiliar a decisão de compra de outros usuários. Além do conteúdo, as empresas devem se ater aos sentimentos, emoções, percepção e ações que são gerados pela divulgação dos produtos/serviços, bem como as suas influências positivas no comportamento do público. 
Como limitação da pesquisa, pode-se citar a literatura ainda pouco explorada sobre o priming virtual, o que poderia ter ajudado para embasar melhor os resultados. Já como sugestão para estudos futuros, indica-se um estudo que analise a ocorrência da ativação do consumo no Instagram e os atributos positivos e negativos das publicações que agem como estímulos ativadores.

\section{Referências}

ASTUTI, B; PUTRI, A. P. Analysis on the Effect of Instagram Use on Consumer Purchase Intensity. Review of Integrative Business and Economics Research, v. 7, n. 2, p. 24-38, 2018. BARDIN, L. Análise de Conteúdo. Lisboa: Edições 70, 2011.

BEARDEN, W. O; NETEMEYER, R. G; TEEL, J. E. Measurement of consumer susceptibility to interpersonal influence. Journal of Consumer Research, v. 15, n. 4, p. 473-481, 1989.

BHARGAVA, A. Proliferation of the Role of Celebrity Endorsement on Consumer Buying Behaviour: A Descriptive Study. Advances in Economics and Business Management, v. 2, n. 3, p. 199-204, 2015.

BHAYANI, A. Word of mouth in consumers purchase decisions: The moderating role of product type. In: $21^{\circ}$ IAMB Conference, International Academy of Management and Business, Canada, p. 1-13, 2016.

BOYD, Danah. Friends, friendsters, and top 8: writing community into being on social network sites. First Monday, v. 11, n. 12, p. 1-12, 2006.

BROWN, J; BRODERICK, A.J; LEE, N. Word of mouth communication within online communities: conceptualizing the online social network. Journal of Interactive Marketing, v. 21, n. 3, p. 2-20, 2007.

CHU, S; KIM, Y. Determinants of consumer engagement in electronic word-of-mouth (eWOM) in social networking sites. International Journal of Advertising, v. 30, n. 1, p. 47-75, 2011.

COOPER, D. R.; SCHINDLER, P. S. Métodos de pesquisa em administração. 10ª ed. Porto Alegre: Bookman, 2011.

DIJKSTERHUIS, A; SMITH, P. K; BAAREN, R.B.V; WIGBOLDUS, D. H. J. The unconscious consumer: effects of environment on consumer behavior. Journal of Consumer Psychology, v. 15, n. 3, p. 193-202, 2005.

DJAFAROVA, E; RUSHWORTH, C. Exploring the credibility of online celebrities' Instagram profiles in influencing the purchase decisions of young female users. Computers in Human Behavior, v. 68, n.1, p. 1-7, 2017.

FAZIO, R. H; SANBONMATSU, D. M; POWELL, M. C; KARDES, F. R. On the Automatic Activation of Attitudes. Journal of Personality and Social Psychology, v. 50 n. 2, p. 229-238, 1986.

FLICK, U.. Uma introdução à pesquisa qualitativa. 3. ed. Porto Alegre: Bookman, 2008.

GODOY, A. S. Introdução à pesquisa qualitativa e suas possibilidades. Revista de Administração de Empresas, São Paulo, v. 35, n. 2, p. 57-63, mar./abr. 1995a.

GOMES, R.. A análise de dados em pesquisa qualitativa. In: MINAYO, M. C. de S. (Org.) Pesquisa Social. Teoria, método e criatividade. 18. ed. Petrópolis: Vozes, 2001. 
GRANOVETTER, M. S. The strength of weak ties. American journal of sociology, v. 78, n. 6 , 1360-1380, 1973.

HERMIDA, A. FLETCHER, F; KORRELL, D; LOGAN, D. Your Friend as Editor: The Shift to the Personalized Social News Stream. In: The Future of Journalism Conference. Cardiff: Cardiff University, 2011.

HEINONEN, K. Consumer activity in social media: Managerial approaches to consumers' social media behavior. Journal of Consumer Behaviour, v. 10, n. 6, p. 356-364, 2011.

HOFFMANN, C. A. K. O comportamento do consumidor, o boca a boca eletrônico (eBAB) e as redes sociais on-line: conhecimento atual e direções futuras. Revista FAE, v. 20, n. 1, p. 27 41, jan./jun., 2017.

IOANĂS, E; STOICA, I. Social Media and its Impact on Consumers Behavior. International Journal of Economic Practices and Theories, v. 4, n. 2, p. 295-303, 2014.

KAPETANAKI, A; BERTELE, K; BRENNAN, R. Social marketing through social media: the effects of user-generated content. Disponível em: $\langle$ https://ssrn.com/abstract=3112847 $>$ Acesso em: 20 Jul. 2018.

KOMALADEWI, R; INDIKA, D. A Review of Consumer Purchase Decision on Low Cost Green Car in West Java, Indonesia. Review of Integrative Business and Economics Research, v. 6, n. 2, p.172-184, 2017.

KREFT, J; KARWAT, Z. The Opinion of Facebook Friends as the Most Reliable Recommendation of Products and Services in Poland: The Evolution of Purchase Pathways in Social Media. Handel Wewnętrzny, v. 5, n. 370, p. 250-259, 2017.

LEITE, Y. V. P; MORAES, W. F. A. de; SALAZAR, V. S. Teoria adaptativa e ATLAS.ti 7: uma parceria para o desenvolvimento de framework de empreendedorismo internacional. Revista Gestão \& Tecnologia, Pedro Leopoldo, v. 16, n. 2, p. 153-176, mai./ago. 2016.

MASHHADI, M; HASHEMIAMIN, A. The impact of corporate social responsibility indicators on consumer behavior: a case study: electronic and quasi-electronic customers of persian carpet co. Revista QUID, v. 1, n. 1, p. 2516-2528, 2017.

NUNES, R. H; FERREIRA, J. B; FREITAS, A. S. de; RAMOS, F. L. Efeitos das recomendações de líderes de opinião em mídias sociais sobre a intenção de compra de seus seguidores. Revista Brasileira de Gestão e Negócios, v. 20, n.1, p. 57-73, 2018.

PACHECO JUNIOR, J. C. S; DAMACENA, C; BRONZATTI, R. Pré-ativação: o efeito priming nos estudos sobre o comportamento do consumidor. Estudos e Pesquisas em Psicologia, v. 15, n. 1, p. 284-309, 2015.

PAIVA JÚNIOR, F. G. de; LEÃO, A. L. M. de S.; MELLO, S. C. B. de. Validade e Confiabilidade na Pesquisa Qualitativa em Administração. Revista de Ciências da Administração, v. 13, n. 31, p. 190-209, set/dez. 2011.

PARK, D; LEE, J. eWOM overload and its effect on consumer behavioral intention depending on consumer involvement, Electronic Commerce Research and Applications, v. 7, n. 4, p. 386398, 2008.

PRIMO, A. O aspecto relacional das interações na Web 2.0. E- Compós, Brasília, v. 9, p. 1-21, 2007.

RADONSA, D. L; GROHMANN, M. Z; FREITAS, D. O; BATTISTELLA, L. F. Alienação do consumidor e influência dos grupos de referência: estudo exploratório em busca de relações. Revista Administração em Diálogo, v.16, n.2, p.189-215, 2014. 
RECUERO, Raquel. Diga-me com quem falas e dir-te-ei quem és: a conversação mediada pelo computador e as redes sociais na internet. Famecos, Porto Alegre, n. 38, p. 118-128, 2009.

SCARABOTO, D; ROSSI, C. A. V; Costa, D. How Consumers Persuade Each Other: Rhetorical Strategies of Interpersonal Influence in Online Communities. Brazilian Administration Review, v. 9, n. 3, p. 246-267, 2012.

SCHMIDT, A. A; ARAUJO, F. A; FINOCCHIO, C. P. S; RODRIGUES, W. O. P.

Influência das mídias sociais no comportamento de compra de consumidores fitness. Rev. Eletrônica de Gestão e Serviços, v. 9, n. 1, p. 2309-2327, Jan./Jun., 2018.

SOLOMON, Michael R. O comportamento do consumidor: comprando, possuindo e sendo. 12. ed. Porto Alegre: Bookman, 2016.

STAKE, R. E. Pesquisa qualitativa: Estudando como as coisas funcionam. Porto Alegre: Penso, 2011.

TUBENCHLAK, D. B; FAVERI, D. de; ZANINI, M. T; GOLDSZMIDT, R. Motivações da Comunicação Boca a Boca Eletrônica Positiva entre Consumidores no Facebook. Revista de Administração Contemporânea, Rio de Janeiro, v. 19, n. 1, p. 107-126, Jan-Fev, 2015.

TURČÍNKOVÁ, J; MOISIDIS, J. Impact of reference groups on The teenagers' buying process of clothing in the czech republic. Acta Universitatis Agriculturae Et Silviculturae Mendelianae Brunensis, v. 54, n. 7, p. 489-496, 2011.

VINEREAN, S; CETINA, I; DUMITRESCU, L; TICHINDELEAN, M. The Effects of Social Media Marketing on Online Consumer Behavior. International Journal of Business and Management, v. 8, n. 14, p. 66-79, 2013.

WALTER, S. A; BACH, T. M. Adeus papel, marca-textos, tesoura e cola: inovando o processo de análise de conteúdo por meio do Atlas.ti. Administração: Ensino e Pesquisa Rio de Janeiro, v. 16, n. 2, p. 275-308, 2015.

WATERLOO, S. F; BAUMGARTNER, S. E; PETER, J; VALKENBURG, P. M. Norms of online expressions of emotion: Comparing Facebook, Twitter, Instagram, and WhatsApp. New media \& Society, v. 20, n. 5, p. 1813-1831, 2018.

ZAMPIER, M. A.; TAKAHASHI, A. R. W. Competências empreendedoras e processos de aprendizagem empreendedora: modelo conceitual de pesquisa. Cadernos EBAPE, v. 9, p. 564$585,2011$.

ZUCCO, F.D.; PIANEZZER, D.; FALASTER, C. Efeitos dos laços sociais, confiança e influência interpessoal na compra online. Razón y Palabra, v. 21, n. 96, p. 395-416, 2017. 